\title{
Sexual Pleasure Matters (Especially for Women) - Data from the German Sexuality and Health Survey (GeSiD)
}

\author{
Verena Klein $^{1,2}$ (D) Ellen Laan ${ }^{3} \cdot$ Franziska Brunner $^{1} \cdot$ Peer Briken $^{1}$
}

Accepted: 28 January 2022 / Published online: 19 February 2022

(c) The Author(s) 2022

\begin{abstract}
Introduction Sexual pleasure has been a neglected issue in sexual health policies. Emerging trends in public health, however, emphasize the importance of sexual pleasure in preventing negative sexual health outcomes.

Methods Using data from the German Sexuality and Health Survey (GeSiD), we tested the assumption that sexual pleasure is associated with sexual health, including a special focus on the role of gender. Participants were interviewed about their sexual experiences and health between October 2018 and September 2019. The analytical sample included 3472 partnered and single women and men who had been sexually active with a partner in the past 12 months. We examined if sexual pleasure was associated with various sexual health indicators (i.e., communication about sexually transmitted infections (STIs), condom use, and absence of sexual problems).

Results Women reported less sexual pleasure than men. Results further indicate that sexual pleasure was associated with more sexual health indicators in women than in men.

Conclusions Supporting emerging trends in public health our results emphasize the importance of sexual pleasure in preventing negative sexual health outcomes.

Policy Implications.

To promote (especially women's) sexual health, our results call for the implementation of comprehensive sexuality education programs that focus on more positive aspects of sex, such as sexual pleasure and agency.
\end{abstract}

Keywords Sexual health $\cdot$ Sexual pleasure $\cdot$ Gender differences $\cdot$ Representative data $\cdot$ Sexuality

Sexual pleasure is broadly defined as "the physical and/ or psychological satisfaction and enjoyment derived from shared or solitary erotic experiences, including thoughts, fantasies, dreams, emotions, and feelings" (World Association of Sexual Health [WHO], 2019). In Western societies, sexual pleasure and its pursuit are seen as some of the most important goals of non-reproductive sexual activity (van Lunsen et al., 2013). With that in mind, it is surprising that sexual pleasure has received scant attention in research (Jones,

Verena Klein

vklein@uke.de

1 Institute for Sex Research, Sexual Medicine, and Forensic Psychiatry, University Medical Center Hamburg-Eppendorf, Martinistraße 52, 20246 Hamburg, Germany

2 Department of Psychology, University of Michigan, Ann Arbor, USA

3 Department of Sexology and Psychosomatic Gynaecology, Amsterdam University Medical Center, University of Amsterdam, Amsterdam, The Netherlands
2019). Although the World Health Organization (World Health Organization, 2006) has acknowledged the possibility of having pleasurable sexual experiences in its definition of sexual health, the sexual health discourse has traditionally had a disproportionate focus on the negative outcomes of sex, like sexually transmitted infections (STIs), sexual dysfunctions, and unwanted pregnancy (Fine \& McClelland, 2006; Higgins \& Hirsch, 2007, Mitchell et al., 2021). Emerging trends in public health, however, challenge this view and emphasize the importance of sexual pleasure for sexual health and sexual rights (Ford et al., 2019; Gruskin \& Kismödi, 2020; Kismödi et al., 2017; Landers \& Kapadia, 2020).

\section{Sexual Pleasure and Sexual Health}

Why does sexual pleasure matter for sexual and public health? First and foremost, sexual pleasure is an integral part of sexual well-being and overall well-being (Anderson, 
2013; Robinson et al., 2002). Integrating sexual pleasure into public health policies and sex education was found to increase people's knowledge about sexuality, sexual communication, and safer sex behaviors - all crucial aspects of sexual and public health (Ford et al., 2019; Higgins \& Hirsch, 2007; Landers \& Kapadia, 2020). For instance, one sexual health model predicts that women and men who enjoy and seek sexual pleasure are more likely to make adaptive, health-promoting decisions (e.g., to negotiate safe-sex practices) (Robinson et al., 2002). That said, sex education is more effective when combining healthy images of desire and pleasure alongside safer sex messaging (Philpott et al., 2006), rather than just focusing on negative consequences of sex. Despite the theoretically established importance of sexual pleasure in the context of sexual health, there remains a paucity of empirical research concerning its associations with specific sexual health outcomes. In the present study, we aimed to test the assumptions made by prior research empirically. More precisely, we investigated whether people who experience sex as more pleasurable are more likely to make sexually healthy decisions (e.g., communicate about STI risk with a new partner, negotiating condoms use, use condoms).

Of course, the sexual pleasure discourse is broader than merely its relationship with sexual health behavior. A second aim of this paper was to investigate, in line with other representative surveys (e.g., National Survey of Sexual Health and Behavior (NSSHB)), pleasurable sex and its associations with different sexual behaviors. For instance, different waves of NSSHB assessed the prevalence and general predictors of pleasurable sex. This US nationally representative survey asked about participant's experience with pleasure during the last partnered sexual event among ethnically diverse samples (Townes et al., 2021) and various age groups (Schick et al., 2010). Another line of research examined sexual behaviors (Herbenick et al., 2019) and sexual techniques related to (women's) sexual pleasure (Herbenick et al., 2018), as well as lack of pleasure relative to sexual pain (Carter et al., 2019).

\section{Sexual Pleasure and Gender}

Sexual pleasure is crucial in shaping individuals' sexual well-being (Abramson \& Pinkerton, 2002). For instance, women are more likely to report higher rates of sexual desire when their pleasure is prioritized (Rubin et al., 2019). Experiences of sexual pleasure are, however, embedded in a gendered context that disadvantages women (i.e., the pleasure gap; for a review, see Laan et al., 2021), and in most contemporary societies, women's sexual pleasure is still generally subordinated to men's pleasure (Hall, 2019; Hall \& Graham, 2012). Evidence suggests that in the heterosexual context, sex that women experience is different, and substantially less positive than the sex that men experience (Conley \& Klein, 2022). Research shows that women experience orgasms at far lower rates than men (e.g., Conley et al., 2011; Frederick et al., 2018), that pain associated with sex is much more common among women (Carter et al., 2019; Elmerstig et al., 2013), and that women are subject to far more violence in heterosexual sexual encounters than their male counterparts (Brunner et al., 2021; World Health Organization, 2013). We aimed, therefore, to investigate the relationship between sexual pleasure and sexual health outcomes for women and men separately to examine, whether there are gender differences in these relationships.

\section{The Present Study}

Using a representative population sample, we examined the association between sexual pleasure and sexual health outcomes, with a special focus on gender. Sexual pleasure can be experienced through different kinds of rewards and sexual behaviors such as feeling sexually aroused or connected to a partner (Pascoal et al., 2016). Most national representative sex surveys so far have mostly used only one item measures to assess sexual pleasure. For instance, the National Health and Social Life Survey (NHSLS; Laumann et al., 1994) that surveyed adults in the USA included one item on pleasure ("...how physically pleasurable did you find your sexual relationship...?") (for a critical discussion, see McClelland, 2010). In the present study, we used seven items from the original Amsterdam Sexual Pleasure Index (ASPI; Vol 0.1; Werner et al., 2021) that operationalize pleasure in a more in-depth and multifaceted way. Defining sexual pleasure broadly as "the enjoyment one derives from (individually or mutually) rewarding sexual activities" (e.g., Pascoal et al., 2016; Philpott et al., 2006), the ASPI assesses individuals tendency to experience sexual pleasure (Werner et al., 2021).

The aims of the present study were twofold. First, we examined gender differences in reported sexual pleasure. Second, we tested the hypothesis that sexual pleasure has a positive relationship with sexual health outcomes. To do so, we included various indicators of sexual health, long with more classic sexual health indicators, such as communication about sexually transmitted infections (STIs) and condom use. Since the expansive definition of sexual health developed by the WHO includes concepts such as the absence of disease, we conceptualize sexual health and wellbeing more broadly by additionally assessing the absence of sexual problems (e.g., arousal difficulties, pain during sex).

Having a more pleasure-inclusive concept of sexual health and well-being, we additionally examined the relationship between pleasure and orgasm frequency and engagement in oral sex. Orgasm frequency and orgasm 
consistency have been shown to increase women's wellbeing and satisfaction (e.g., Laan et al., 2021). So as not to suggest that pleasurable sex is or should be limited to penetrative sex, oral sex engagement was also included, as oral stimulation of the glans clitoris is the most reliable source for women's orgasm experiences (e.g., Frederick et al., 2018).

\section{Method}

\section{Data Collection and Procedure}

Using a two-stage stratified and clustered probability sample design, data were collected as part of the German national sex survey (German Health and Sexuality Survey (GeSiD) Study, for a detailed description of the survey methods and recruitment strategy, see Matthiesen et al., 2021). Interviews were conducted between October 2018 and September 2019 by a social research institution (KANTAR). After providing informed consent, participants proceeded to take part in a combination of a face-to-face computer-assisted personal interview and a computer-assisted self-interview. The interviews covered different areas of sexual (health) behavior such as sexual experience; same sex experiences; gender identity and sexual orientation; safer sex practices; and sexual attitudes. Participants received a total amount of 30 Euro compensation for participation. The Ethical Board of the State Psychotherapy Chamber in Hamburg approved the study procedures.

The response rate was 30.2\% (AAPOR Response Rate 4); and the cooperation rate $37.9 \%$ (AAPOR Cooperation Rate 4). Data were weighted to adjust for unequal probabilities of selection in terms of age, sex, age, nationality, education, and region which led to it being broadly representative of the German population compared to the 2018 Mikrozensus (Census).

\section{Sample}

The analytical, weighted sample for the present study included 3472 partnered and single cisgender women and men ( $46.3 \%$ women, $53.7 \%$ men) who had been sexually active (with a partner) in the past 12 months and who completed the sexual pleasure measure. All participants were German-speaking residents, aged between 18 and 75 years $(M=44.22, S D=15.73)$ (for a detailed sample description, see Table 1). No forced-choice response format was chosen, which explains why the sample size varies over the dependent variables.

\section{Measures}

\section{Sexual Pleasure}

Sexual pleasure was measured with seven items from the Amsterdam Sexual Pleasure Index that showed acceptable to excellent psychometric properties in a validation study (Werner et al., 2021). Participants indicated their impressions of the amount of pleasure they derive from sexual acts, whereby most items focused on shared experiences with a partner (e.g., "I can engage in sex in such a way that I really enjoy it.," "I feel connected to my partner during sex.," "I enjoy it when my body reacts to sexual stimuli.," "I love to show my partner how excited I am during sex.") (Werner et al., 2021). Items were rated on a 5-point scale ranging from totally disagree to totally agree. These items were combined into a pleasure scale, with higher numbers indicating greater pleasure. Cronbach's alpha for the scale in the present sample was 0.84 .

\section{Sexual Health Outcomes}

\section{Sexual Communication About STIs and Condom Use}

People who were single at the time of participation and sexually active with a partner in the last 12 months were asked, "Please think of the last time you had sex. Did you discuss HIV/Aids and sexually transmitted infections before having sex?" Condom use discussion was assessed with the following item: "Did you discuss the use of condoms before having sex?."

Partnered women and men who were sexually active in the last 12 months were asked to answer the items on communication about STIs and condom use based on their experiences with their current, steady partner using the following two items: "Think back to the time when you first had sex with (...): Did you talk about HIV/ Aids and other sexually transmitted infections before the first time you had sex with (...)? and "Did you discuss the use of condoms before having sex with (...) for the first time?" For all sexual communication about STIs and condom use items, participants either indicated yes or no.

\section{Safer Sex Intention}

We asked participants: "Do you currently have condoms at home or in your bag?" on a binary scale (yes/no). 
Table 1 Sociodemographic characteristics and sexual health indicators of the sample $(N=3472)$

\begin{tabular}{|c|c|c|}
\hline & \multicolumn{2}{|c|}{$\%$ (unweighted $n$; weighted $n$ ) } \\
\hline \multicolumn{3}{|l|}{ Age } \\
\hline $18-25$ & \multicolumn{2}{|l|}{$11.5(531 ; 400)$} \\
\hline $26-35$ & \multicolumn{2}{|l|}{$20.7(935 ; 720)$} \\
\hline $36-45$ & \multicolumn{2}{|l|}{$19.1(674 ; 664)$} \\
\hline $46-55$ & \multicolumn{2}{|l|}{$24.3(679 ; 844)$} \\
\hline $56-65$ & \multicolumn{2}{|l|}{$16.5(530 ; 572)$} \\
\hline $66-75$ & \multicolumn{2}{|l|}{$7.9(248 ; 273)$} \\
\hline \multicolumn{3}{|l|}{ Gender } \\
\hline Female & \multicolumn{2}{|l|}{$46.3(1,826 ; 1,606)$} \\
\hline Male & \multicolumn{2}{|l|}{$53.7(1,771 ; 1,865)$} \\
\hline \multicolumn{3}{|l|}{ Sexual identity } \\
\hline Exclusively heterosexual & \multicolumn{2}{|l|}{$96.8(3,405 ; 3,270)$} \\
\hline \multirow[t]{2}{*}{ Non-exclusively heterosexual } & \multicolumn{2}{|l|}{$3.2(125 ; 108)$} \\
\hline & Women & Men \\
\hline \multicolumn{3}{|c|}{ Singles' sexual communication about STIs } \\
\hline Yes & $35(59,48)$ & $29.7(64,79)$ \\
\hline No & $65(122,90)$ & $70.3(198,188)$ \\
\hline \multicolumn{3}{|c|}{ Singles' sexual communication about condom use } \\
\hline Yes & $65.4(127,92)$ & $65(168,177)$ \\
\hline No & $34.6(57,48)$ & $35(100,95)$ \\
\hline \multicolumn{3}{|l|}{ Safer sex intention } \\
\hline Yes & $30.7(593,492)$ & $30.9(536,573)$ \\
\hline No & $69.3(1,223,1,109)$ & $69.1(1,228,1,283)$ \\
\hline \multicolumn{3}{|c|}{ Partnered women's and men's sexual communication about STIs } \\
\hline Yes & $31.9(521,429)$ & $30(420,440)$ \\
\hline No & $68.1(991,915)$ & $70(969,1029)$ \\
\hline \multicolumn{3}{|c|}{ Partnered women's and men's sexual communication about condom use } \\
\hline Yes & $58.9(964,823)$ & $57.7(878,890)$ \\
\hline No & $41.1(604,573)$ & $42.3(581,652)$ \\
\hline \multicolumn{3}{|l|}{ Condom use } \\
\hline Yes & $49.5(870,705)$ & $46.4(712,719)$ \\
\hline No & $50.5(723,721)$ & $53.6(757,831)$ \\
\hline \multicolumn{3}{|l|}{ Orgasm occurrence } \\
\hline Yes & $75.4(1,175,1,055)$ & $95.4(1,417,1,486)$ \\
\hline No & $24.6(408,343)$ & $4.6(60,72)$ \\
\hline \multicolumn{3}{|l|}{ Absence sexual problems } \\
\hline No & $45.8(783,664)$ & $32.2(561,557)$ \\
\hline Yes & $54.2(900,785)$ & $67.8(1,097,1,175)$ \\
\hline
\end{tabular}

Numbers do not always add up to the sample size due to missing information. Percentages are based on weighted analyses

\section{Condom Use}

Partnered individuals additionally answered the item: "Did you use a condom when you had sex with (...) for the first time?" Again, participants were provided with a binary yes/ no response format.

\section{Absence of Sexual Problems}

Participants were asked to read the following instruction: "Please specify for each of the following difficulties whether you have ever experienced it over a period of several months." Women were then presented with descriptions of hypoactive sexual desire, arousal difficulties, orgasm difficulties, and pain during sex. Men indicated whether they had experienced hypoactive sexual desire, erectile difficulties, difficulties with premature ejaculation, or delayed ejaculation. Participants who indicated having one of the listed problems specified if they experienced this problem in the past 12 months. Based on those yes/no answers, we build the variable absence of sexual problems by including all participants that indicated having at least one problem during the last 12 months in the "no" category and participants without any problems in the "yes" category. 


\section{Orgasm Occurrence}

Participants indicated if they had an orgasm during their last sexual encounter ("Did you have an orgasm the last time you had sex?"). The response scale included the options ("No," "Yes, once," or "Yes, several"). We merged "yes, once" and "yes, several" into a single "yes" category.

\section{Engagement in Oral Sex}

Participants indicated their engagement in oral sex as one option on a scale that measured different sexual behaviors ("Think of the last time you had sex. What type of sex did you have then?") on a yes/no scale.

\section{Sociodemographic Characteristics}

We asked for current relationship status dichotomized (i.e., single and married/in a relationship). In addition, the following question was used to address sexual identity: "Please select the answer which describes best how you see yourself at present?" Answers were anchored on a 7-point scale. The first five points ranged from $1=$ exclusively heterosexual to $5=$ exclusively homosexual/gay, while the final two points denoted asexual and other identities (see Table 1).

\section{Statistical Analysis}

Statistical analysis was based on the weighted sample using the "complex sampling" module in IBM SPSS Statistics, version 27. Given the discussed gendered context of pleasure, a Levene test was calculated to test whether variances in the sexual pleasure measure differed between genders. Gender differences were examined using $t$-test. Logistic regression analyses adjusted for age were calculated to examine the strength of the association between sexual pleasure as predictor and sexual health indicators as outcome variables. Considering that some of the sexual health outcomes (e.g., talking about STIs, using a condom) could vary by age and relationship status, logistic regression analysis was adjusted for age. The results of the logistic regression for the outcomes sexual communication about condom use and sexual communication about STIs were reported for single and partnered people separately.

\section{Results}

\section{Gender Differences in Sexual Pleasure}

Results of the Levene's test indicated that equality of variances for the women and men sample was not given, $F(1$, $3793)=19.98, p<0.001$. Consequently, a $t$-statistic not assuming homogeneity of variance was calculated. Women reported significantly lower sexual pleasure $(M=3.84 ; S D=0.79)$ than did men $(M=3.99 ; S D=0.70), t(3243)=5.90, p<0.001$.

\section{Sexual Health Outcomes}

Descriptive statistics for all dependent variables are shown in Table 1. As presented in Table 1, women reported lower percentages of orgasms than men did. Absence of sexual problems was more commonly reported by men than women (see Table 1).

In women, sexual pleasure showed an association with safer sex intention. Among partnered women, we also found a positive association between pleasure and sexual communication about STIs and condom use, as well as with actual condom use. Sexual pleasure was significantly associated

Table 2 Results of the logistic regression analyses predicting sexual health outcomes as a function of sexual pleasure in the women's sample

\begin{tabular}{|c|c|c|c|c|}
\hline Dependent variables & $N^{\mathrm{a}}$ & Nagelkerke $R^{2}$ & OR & $95 \% C I$ \\
\hline Singles' sexual communication about STIs ${ }^{\mathrm{b}}$ & 138 & .044 & 1.04 & $.97-1.12$ \\
\hline Singles' sexual communication about condom use ${ }^{b}$ & 139 & .035 & 1.00 & $.93-1.07$ \\
\hline Safer sex intention & 1600 & .008 & $1.03 *$ & $1.00-1.05$ \\
\hline Partnered women's sexual communication about STIs ${ }^{c}$ & 1344 & .078 & $1.03 *$ & $1.01-1.06$ \\
\hline Partnered women's sexual communication about condom use ${ }^{c}$ & 1395 & .071 & $1.04 * *$ & $1.01-1.06$ \\
\hline Condom use ${ }^{c}$ & 1427 & .135 & $1.03 * *$ & $1.01-1.05$ \\
\hline Orgasm occurrence & 1398 & .11 & $1.12 * * *$ & $1.09-1.15$ \\
\hline Engagement in oral sex & 1427 & .097 & $1.10 * * *$ & $1.08-1.13$ \\
\hline Absence of sexual problems & 1449 & .140 & $1.15 * * *$ & $1.11-1.17$ \\
\hline
\end{tabular}

$* p<.05 ; * * p<.01 ; * * * p<.001$

${ }^{\mathrm{a}}$ Total sample size of participants that answered that dependent variable

b singles

${ }^{c}$ partnered women 
with the absence of sexual problems, orgasm frequency, and engagement in oral sex in the total women's sample (see Table 2).

In the men's sample, sexual pleasure was not associated with communication about STIs, communication about condom use, safer sex intention, or condom use. Results further indicated that sexual pleasure was associated with the absence of sexual problems, engagement in oral sex, and orgasm frequency in the men's sample (see Table 3).

\section{Discussion}

Research and sexual health policies have a long history of neglecting the role of sexual pleasure in preventing negative sexual outcomes (Ford et al., 2019). Our results point to the importance of sexual pleasure for sexual health - and even more pronounced for women. Aligning with the current public health discourse, sexual pleasure in our study was associated with making sexually healthy decisions (e.g., condom use, STI communication) and sexually satisfying experiences (e.g., oral sex engagement, absence of sexual problems, and orgasm frequency).

Although odds rations were overall small, sexual pleasure was associated with more sexual health indicators in women than in men. Ample evidence indicates that both women and men value men's sexual pleasure more, and men are more likely to demand it during an encounter (McCabe et al., 2010; McClelland, 2011; Muehlenhard \& Shippee, 2010). Globally speaking, men seem to have a better access to sexual pleasure and autonomy than women do (Hall, 2019; Higgins \& Hirsch, 2007). Alingning with this assumption, in our study, men were more likely to report experiencing sexual pleasure than women. Based on those observed gender differences, it could be assumed that whereas men's pleasure seems to be a "normal," present condition, women's sexual pleasure seems to be more often absent, an add-on, or at least less prioritized. That said, the results might not a function of pleasure being more important for women, but rather men's scores lack variability (i.e., for men, sex is almost invariably pleasurable). This lower variability in scores might explain why sexual pleasure plays a more predictive role in women's sexual health than in men's.

Interestingly, pleasure had a greater influence on communication about STIs and condom use for partnered women than it did for single women. Public health research has emphasized that safer sex communication is interwoven with gendered power inequalities (Wingood \& DiClemente, 2000). Women face more stigma when negotiating condom use (Peasant et al., 2015; Woolf \& Maisto, 2008) as well as when expressing themselves in a sexually assertive manner (Klein et al., 2019). Women and men are especially likely to conform to traditional gender expectations surrounding sexual behavior (female submission vs. male dominance) in initial states of dating (Eaton \& Rose, 2011). Sexual communication and safer sex negotiations, however, need some degree of assertiveness, which might undermine women's conformity to gender norm expectations in the casual context. Nevertheless, the sample size of single women was small in the present study, what might explain the different role pleasure plays for single versus partnered women when it comes to communication about STIs and condom use.

Since our data are cross-sectional, all that is known is that sexual pleasure and the investigated sexual health indicators are associated. That said, it is possible that for instance being able to communicate about STI risk makes sex more pleasurable (by removing concerns about STIs etc.) or STI communication might be a good proxy for comfort with sexuality. There is also the possibility that sexual pleasure and safer sex practices may be linked via another third factor such as being comfortable with one's sexuality. Moreover, we have focused on condom use as main safe-sex practice, which
Table 3 Results of the logistic regression analyses predicting sexual health outcomes as a function of sexual pleasure in the men's sample

\begin{tabular}{|c|c|c|c|c|}
\hline Dependent variables & $N^{\mathrm{a}}$ & Nagelkerke $R^{2}$ & OR & $95 \% C I$ \\
\hline Singles' sexual communication about STIs ${ }^{\mathrm{b}}$ & 267 & .015 & 1.02 & $0.95-1.09$ \\
\hline Singles' sexual communication about condom use ${ }^{b}$ & 273 & .065 & 0.93 & $0.86-1.01$ \\
\hline Safer sex intention & 1857 & .004 & 1.02 & $0.99-1.05$ \\
\hline Partnered men's sexual communication about STIs ${ }^{c}$ & 1470 & .055 & 1.01 & $0.98-1.04$ \\
\hline Partnered men's sexual communication about condom use ${ }^{c}$ & 1542 & .077 & 1.00 & $0.97-1.03$ \\
\hline Condom use ${ }^{c}$ & 1550 & .131 & 0.99 & $0.96-1.02$ \\
\hline Orgasm occurrence & 1558 & .023 & $1.07 * *$ & $1.01-1.13$ \\
\hline Engagement in oral sex & 1540 & .086 & $1.08 * * *$ & $1.05-1.12$ \\
\hline Absence of sexual problems & 1732 & .022 & $1.05 * * *$ & $1.03-1.08$ \\
\hline
\end{tabular}


leaves out other safe-sex practices mostly practice by women who have sex with women such as dental dams and gloves. A closer examination of the interplay between sexual pleasure and sexual health among gender diverse samples would be an interesting venue for future research. Another limitation is that we have assessed some health behaviors such as condom use discussion retrospectively meaning that single and partnered people answered questions about different time periods. Consequently, we cannot exclude the possibility of recall biases. Although our cross-sectional, correlational study points to associations between sexual pleasure and sexual health behaviors, prospective studies that assess the influence of sexual pleasure on sexual risk and risk-reduction practices are warranted.

The present study included a large, representative sample with a balanced distribution of women and men; it is however important to keep in mind that our sample draws from Germany, a Western liberal country when it comes to sexual attitudes (i.e., acceptance of same-sex behavior, abortion, sex work; Klein \& Brunner, 2018). Sexual pleasure has different meanings and varies in ascribed significance over different cultures (Hall \& Graham, 2012), which limits the generalizability of our result to other cultural contexts. Societal and cultural judgements about sex, shame, and guilt have negative effects on both sexual pleasure and health (Hull, 2008).

\section{Conclusion}

Sex education as well as research on adolescent sexual development has primarily focused on the prevention of negative health outcomes (e.g., unwanted pregnancy, sexually transmitted infections), which has especially influenced the perception of young women's sexuality (Fine \& McClelland, 2006; Tolman \& McClelland, 2011). Given that young women's sexual development is taking place in a social context saturated by often conflicting messages about women's sexuality, sexual desire, and pleasure (Fine \& McClelland, 2006; Klein et al., 2018), our results point to the importance of comprehensive sexuality education programs that promotes women's pleasure. In supporting young women and men to develop a satisfying, and pleasurable approach to sexuality and close relationships, sex education for young men about women's pleasure is also needed. Promoting "cliteracy," teaching girls and boys that biologically speaking no gender differences in the capacity for pleasure and the mechanisms of pleasure exist, should be an important part of pleasure-prioritized sex education (Laan et al., 2021).

Our results indicate that more effort is needed to close the pleasure gap between women and men. Continuing to underestimate pleasure as a means to a healthy sex life will only hinder our ability to understand how to improve sexual health, especially for women. In order to promote the sexual health of women especially, our results call for the implementation of policies and comprehensive education plans that focus on more positive aspects of sex, like pleasure, desire, and agency (Anderson, 2013; Ford et al., 2019; Gruskin \& Kismödi, 2020).

Funding Open Access funding enabled and organized by Projekt DEAL. The study was funded by the German Federal Centre for Health Education (BZgA) (Grant numbers: Z2/25.5.2.1/18; Z2/25.5.2.1/20). This project has also received funding from the European Union's Horizon 2020 research and innovation programme under the Marie Skłodowska-Curie grant agreement No. 845508 awarded to Verena Klein.

Availability of Data and Material Data are available on request.

\section{Declarations}

Conflict of Interest The authors declare no competing interests.

Open Access This article is licensed under a Creative Commons Attribution 4.0 International License, which permits use, sharing, adaptation, distribution and reproduction in any medium or format, as long as you give appropriate credit to the original author(s) and the source, provide a link to the Creative Commons licence, and indicate if changes were made. The images or other third party material in this article are included in the article's Creative Commons licence, unless indicated otherwise in a credit line to the material. If material is not included in the article's Creative Commons licence and your intended use is not permitted by statutory regulation or exceeds the permitted use, you will need to obtain permission directly from the copyright holder. To view a copy of this licence, visit http://creativecommons.org/licenses/by/4.0/.

\section{References}

Abramson, P. R., \& Pinkerton, S. D. (2002). With pleasure: Thoughts on the nature of human sexuality. Oxford University Press.

Anderson, R. M. (2013). Positive sexuality and its impact on overall well-being. Bundesgesundheitsblatt - Gesundheitsforschung - Gesundheitsschutz, 56(2), 208-214. https://doi.org/10.1007/ s00103-012-1607-z

Brunner, F., Tozdan, S., Klein, V., Dekker, A., \& Briken, P. (2021). Lebenszeitprävalenz des Erlebens von Sex und sexueller Berührung gegen den eigenen Willen sowie Zusammenhänge mit gesundheitsbezogenen Faktoren. BundesgesundheitsblattGesundheitsforschung-Gesundheitsschutz, 1-16.

Carter, A., Ford, J. V., Luetke, M., Fu, T. C. J., Townes, A., Hensel, D. J., \& Herbenick, D. (2019). "Fulfilling his needs, not mine": Reasons for not talking about painful sex and associations with lack of pleasure in a nationally representative sample of women in the United States. The Journal of Sexual Medicine, 16(12), 1953-1965. https://doi.org/10.1016/j.jsxm.2019.08.016

Conley, T. D., \& Klein, V. (2022). Women Get Worse Sex: A Confound in the Explanation of Gender Differences in Sexuality. Perspectives on Psychological Science. https://doi.org/10.1177/ 17456916211041598

Conley, T. D., Moors, A. C., Matsick, J. L., Ziegler, A., \& Valentine, B. A. (2011). Women, men, and the bedroom: Methodological and 
conceptual insights that narrow, reframe, and eliminate gender differences in sexuality. Current Directions in Psychological Science, 20(5), 296-300. https://doi.org/10.1177/0963721411418467

Eaton, A. A., \& Rose, S. (2011). Has dating become more egalitarian? A 35 year review using Sex Roles. Sex Roles, 64(11-12), 843-862. https://doi.org/10.1007/s11199-011-9957-9

Elmerstig, E., Wijma, B., \& Swahnberg, K. (2013). Prioritizing the partner's enjoyment: A population-based study on young Swedish women with experience of pain during vaginal intercourse. Journal of Psychosomatic Obstetrics \& Gynecology, 34(2), 82-89. https://doi.org/10.3109/0167482X.2013.793665

Fine, M., \& McClelland, S. (2006). Sexuality education and desire: Still missing after all these years. Harvard Educational Review, 76(3), 297-338

Ford, J. V., Corona Vargas, E., Finotelli, I., Jr., Fortenberry, J. D., Kismödi, E., Philpott, A., \& Coleman, E. (2019). Why pleasure matters: Its global relevance for sexual health, sexual rights and wellbeing. International Journal of Sexual Health, 31(3), 217 230. https://doi.org/10.1080/19317611.2019.1654587

Frederick, D. A., John, H. K. St., Garcia, J. R., \& Lloyd, E. A. (2018). Differences in orgasm frequency among gay, lesbian, bisexual, and heterosexual men and women in a U.S. national sample. Archives of Sexual Behavior, 47(1), 273-288. https:// doi.org/10.1007/s10508-017-0939-z

Gruskin, S., \& Kismödi, E. (2020). A call for (renewed) commitment to sexual health, sexual rights, and sexual pleasure: A matter of health and well-being. American Journal of Public Health, 110(2), 159-160. https://doi.org/10.2105/AJPH.2019.305497

Hall, K. S. K. (2019). Cultural differences in the treatment of sex problems. Current Sexual Health Reports, 11(1), 29-34. https:// doi.org/10.1007/s11930-019-00189-9

Hall, K. S. K., \& Graham, C. A. (2012). Cultural context of sexual pleasure and problems. In K. S. K. Hall \& C. A. Graham (Eds.), The cultural context of sexual pleasure and problems: Psychotherapy with diverse clients (pp. 1-20). Routledge.

Herbenick, D., Fu, T. C., Arter, J., Sanders, S. A., \& Dodge, B. (2018). Women's experiences with genital touching, sexual pleasure, and orgasm: Results from a US probability sample of women ages 18 to 94. Journal of Sex \& Marital Therapy, 44(2), 201-212. https://doi.org/10.1080/0092623X.2017.1346530

Herbenick, D., Fu, T. C., Owens, C., Bartelt, E., Dodge, B., Reece, M., \& Fortenberry, J. D. (2019). Kissing, cuddling, and massage at most recent sexual event: Findings from a US nationally representative probability sample. Journal of Sex \& Marital Therapy, 45(2), 159-172. https://doi.org/10.1080/0092623X.2018.1494648

Higgins, J. A., \& Hirsch, J. S. (2007). The pleasure deficit: Revisiting the "sexuality connection" in reproductive health. International Family Planning Perspectives, 39(4), 240-247. https://doi.org/10. $1363 / 3313307$

Hull, T. H. (2008). Sexual pleasure and wellbeing. International Journal of Sexual Health, 20(1-2), 133-145. https://doi.org/10.1080/ 19317610802157234

Jones, A. (2019). Sex is not a problem: The erasure of pleasure in sexual science research. Sexualities, 22(4), 643-668.

Kismödi, E., Corona, E., Maticka-Tyndale, E., Rubio-Aurioles, E., \& Coleman, E. (2017). Sexual rights as human rights: A guide for the WAS declaration of sexual rights. International Journal of Sexual Health, 29(sup1), 1-92. https://doi.org/10.1080/19317611. 2017.1353865

Klein, V., Becker, I., \& Štulhofer, A. (2018). Parenting, communication about sexuality, and the development of adolescent womens' sexual agency: A longitudinal assessment. Journal of Youth and Adolescence, 47(7), 1486-1498.

Klein, V., \& Brunner, F. (2018). Zwischen Liberalität und Retraditionalisierung - Einstellungen zu sexualitätsbezogenen Themen in
Deutschland. Zeitschrift Für Sexualforschung, 31(03), 250-262. https://doi.org/10.1055/a-0664-4322

Klein, V., Imhoff, R., Reininger, K. M., \& Briken, P. (2019). Perceptions of sexual script deviation in women and men. Archives of Sexual Behavior, 48(2), 631-644. https://doi.org/10.1007/ s10508-018-1280-x

Laan, E., Klein, V., Werner, M., van Lunsen, R., \& Janssen, E. (2021). In pursuit of pleasure: A biopsychosocial perspective on sexual pleasure and gender. International Journal of Sexual Health, 1-21. https://doi.org/10.1080/19317611.2021.1965689

Landers, S., \& Kapadia, F. (2020). The public health of pleasure: Going beyond disease prevention. American Journal of Public Health, 110(2), 140-141. https://doi.org/10.2105/AJPH.2019.305495

Laumann, E. O., Gagnon, J. H., Michael, R. T., \& Michaels, S. (1994). The social organization of sexuality. Sexual practices in the U.S. Chicago, IL: University of Chicago Press.

Matthiesen, S., Pietras, L., Bode, H., Cholmakow-Bodechtel, C., Cerwenka, S., Pfister, M., ... \& Dekker, A. (2021). Methodology of the German National Sex Survey-GeSiD (German Health and Sexuality Survey). The Journal of Sex Research, 58(8), $1008-1018$.

McCabe, J., Tanner, A. E., \& Heiman, J. R. (2010). The impact of gender expectations on meanings of sex and sexuality: Results from a cognitive interview study. Sex Roles, 62(3-4), 252-263. https:// doi.org/10.1007/s11199-009-9723-4

McClelland, S. I. (2010). Intimate justice: A critical analysis of sexual satisfaction. Social and Personality Psychology Compass, 4(9), 663-680. https://doi.org/10.1111/j.1751-9004.2010. 00293.x

McClelland, S. I. (2011). Who is the "self" in self reports of sexual satisfaction? Research and policy implications. Sexuality Research and Social Policy, 8(4), 304-320. https://doi.org/10. 1007/s13178-011-0067-9

Mitchell, K. R., Lewis, R., O'Sullivan, L. F., \& Fortenberry, J. D. (2021). What is sexual wellbeing and why does it matter for public health? The Lancet Public Health. https://doi.org/10. 1016/S2468-2667(21)00099-2

Muehlenhard, C. L., \& Shippee, S. K. (2010). Men's and women's reports of pretending orgasm. Journal of Sex Research, 47(6), 552-567. https://doi.org/10.1080/00224490903171794

Pascoal, P. M., Sanchez, D. T., Raposo, C. F., \& Pechorro, P. (2016). Initial validation of the sexual pleasure scale in clinical and non-clinical samples of partnered heterosexual people. The Journal of Sexual Medicine, 13(9), 1408-1413. https://doi.org/ 10.1016/j.jsxm.2016.06.010

Peasant, C., Parra, G. R., \& Okwumabua, T. M. (2015). Condom negotiation: Findings and future directions. The Journal of Sex Research, 52(4), 470-483. https://doi.org/10.1080/00224499. 2013.868861

Philpott, A., Knerr, W., \& Boydell, V. (2006). Pleasure and prevention: When good sex is safer sex. Reproductive Health Matters, 14(28), 23-31. https://doi.org/10.1016/S0968-8080(06)28254-5

Robinson, B. E., Bockting, W. O., Simon Rosser, B. R., Miner, M., \& Coleman, E. (2002). The sexual health model: Application of a sexological approach to HIV prevention. Health Education Research, 17(1), 43-57. https://doi.org/10.1093/her/17.1.43

Rubin, J. D., Conley, T. D., Klein, V., Liu, J., Lehane, C. M., \& Dammeyer, J. (2019). A cross-national examination of sexual desire: The roles of 'gendered cultural scripts' and 'sexual pleasure' in predicting heterosexual women's desire for sex. Personality and Individual Differences, 151, 109502. https://doi.org/10. 1016/J.PAID.2019.07.012

Schick, V., Herbenick, D., Reece, M., Sanders, S. A., Dodge, B., Middlestadt, S. E., \& Fortenberry, J. D. (2010). Sexual behaviors, condom use, and sexual health of Americans over 50: 
Implications for sexual health promotion for older adults. The Journal of Sexual Medicine, 7, 315-329. https://doi.org/10. 1111/j.1743-6109.2010.02013.x

Tolman, D. L., \& McClelland, S. I. (2011). Normative sexuality development in adolescence: A decade in review, 2000-2009. Journal of Research on Adolescence, 21(1), 242-255.

Townes, A., Thorpe, S., Parmer, T., Wright, B., \& Herbenick, D. (2021). Partnered sexual behaviors, pleasure, and orgasms at last sexual encounter: Findings from a US probability sample of Black women ages 18 to 92 Years. Journal of Sex \& Marital Therapy, 1-15. https://doi.org/10.1080/0092623X.2021.1878315

van Lunsen, R. H. W., Brauer, M., \& Laan, E. (2013). Sex, pleasure and dyspareunia in liberal Northern Europe. In C. Graham \& K. Hall (Eds.), The cultural context of sexual pleasure and problems: Psychotherapy with diverse clients (pp. 335-370). Routledge.

Werner, M. A., van Lunsen, R. H. W., Gaasterland, C., Bloemendaal, L. B. A., \& Laan, E. (2021). The Amsterdam Sexual Pleasure Index (ASPI) Vol. 0.1: Psychometric properties of the first version of a new multidimensional self-report questionnaire of sexual pleasure and its propensities. Manuscript under revision.
Wingood, G. M., \& DiClemente, R. J. (2000). Application of the theory of gender and power to examine HIV-related exposures, risk factors, and effective interventions for women. Health Education \& Behavior, 27(5), 539-565. https://doi.org/10.1177/109019810002700502

Woolf, S. E., \& Maisto, S. A. (2008). Gender differences in condom use behavior? The role of power and partner-type. Sex Roles, 58(9), 689701. https://doi.org/10.1007/s11199-007-9381-3

World Association of Sexual Health. (2019, October 15). Declaration on sexual pleasure. https://worldsexualhealth.net/declaration-onsexual-pleasure

World Health Organization. (2006). Defining sexual health report of a technical consultation on sexual health. Geneva: World Health Organization. Retrieved from http://www.who.int/reproductivehealth/ publications/sexual_health/defining_sexual_health.pdf

World Health Organization. (2013). Global and regional estimates of violence against women: Prevalence and health effects of intimate partner violence and non-partner sexual violence.

Publisher's Note Springer Nature remains neutral with regard to jurisdictional claims in published maps and institutional affiliations. 